$\xi=-1$

\title{
Influence of Ethical Leadership Practices in Developing Trust in Leaders: a Pilot Study on Malaysian Secondary Schools
}

\author{
Sharmini Siva Vikaraman*, Azlin Norhaini Mansor, Mohd Izham Mohd Hamzah \\ Department of Educational Leadership and Policy, Faculty of Education, \\ National University of Malaysia, 43600 Bangi, Malaysia \\ *Corresponding author E-mail: shammyny@yahoo.com
}

\begin{abstract}
Significant school leadership involves the ability to influence, motivate and; change teacher work behavior patterns towards achieving positive work place attitude and organizational goals. This quantitative correlational case study, aims at identifying the level of ethical leadership and trust in leader practiced by leaders, presenting facts and figures that determines the influence of ethical leadership practices in developing trust in leader that is presumed to lead to better work place behaviours. This cross-sectional study is a pilot survey which collected 31 national secondary school teachers' perception on their school principal's ethical leadership practices and their trust on their leaders through an on-line survey. The Ethical Leadership at Work and Trust in Leader questionnaire used in this study were strongly reliable with Cronbach Alpha values of 0.965 and 0.981 respectively. Results showed level of ethical leadership practiced among secondary school principals and trust in their principal are both at high level. Findings also shows that ethical leadership correlated positively in the development of trust in leaders. The two practices of ethical leadership that showed very strong significant impact on developing trust in leaders were integrity and people orientation. The results encourage other researchers to explore the practice of ethical leadership with a larger sample, different variables and aims with the goal of improving leadership roles and teacher work performance.
\end{abstract}

Keywords: Ethical Leadership, Trust in Leaders, Teacher Work Performance

\section{Introduction}

In today's school leadership and management context the role of a principal has diverted to areas of improving a school through better human relationship and values. Looking at current challenges teacher burnout, demotivation, passionless and high teacher job demands Lin in (1) states and suggests organizational trust can highly facilitate positive work commitment; and trust in leader fosters positivity in work place (2). The Malaysian Public Complains Bureau reported that Ministry of Education and State Education Departments were ranked $3^{\text {rd }}$ with most complains by public for the service. Bligh (3) pointed out the importance of trust between leaders and followers; and how trust is built in this dynamic workplace relationship. Leaders and followers share a rare feeling of obeying the words of another through their demonstrated actions and promises. There are trustable characteristics and qualities of a leader that helps the employee in making decisions to trust the leader or not (4-5) that eventually can lead to performing work without hesitation with positive work engagement. Some pertinent issues when there is no or lack of trust in the leader can result in longer approval processes, lack of motivation, high fear and defensiveness. Hence, before the forming of trustworthiness in employee, it is vital for the leader to demonstrate appropriate leadership practices and propensity to trusts that leads the employee to trusting the leader.

Engelbrect and team listed several value based leadership styles transformational, authentic, spiritual and ethical leadership to be effective in building trust in leaders which in turn affects their employee work pattern (6) that could be an alternative to modern leadership styles commonly practiced. Darcy (7) introduced an organizational dilemma - "a crisis of trust" when an organization shows doubts in leaders ethics and eventually lose trust. Frank (8) created the term the "shadow side" of leaders whereby leaders are influenced by negative leadership behaviors that lead to the loss of trust. Davis (9), shared a series of ideals that emerged as significant administrative qualities that were identified to positively influence teacher job satisfaction as - integrity, support and communication. Each quality suggested the dimensions of values and practices. Teachers were much satisfied with their jobs when principals were trustworthy, honest and ethical. Hence, this study looks into a value-based leadership style - ethical leadership practices that in the practice of, could possibly lead to building strong trust between school principals and teachers.

\subsection{Ethical Leadership}

Ethics is defined as "morals" originating from the Greek word "ethos". Ethics is the way an individual thinks and acts which he or she presumes is right or wrong (10), study of what constitutes a moral life and approaches to living a moral life (11). Ethics is reflected in ones behavior by using the proper codes of conducts to make the right decision through effective reasoning and judgment regarding what is right and wrong (12-14).

Brown et al., (15) defined ethical leadership as a leader who abides to moral values, principles and moral conducts in their say, behavior, action and decision making; and being as such he or she is able to inspire their followers to be equally ethical in their drives to achieve a goal. What principles and rules of conduct set by the leader must also be practiced by the leader himself. Trevino et al., (16) added that, ethical leaders has capabilities of playing 
the role of a "moral person" - someone who practices good moral conducts and a "moral manager" - someone who can lead with ethical or moral conducts to achieve goals and develop the follower into a better person. Bello (17) compiled ethical leadership characteristics as exhibition of ethical qualities such as - integrity, honesty, trustworthiness, people orientation, empowering and motivating. Among vast dimensions of ethical leadership practices, this case study explored the Ethical Leadership at Workplace (ELW) dimensions namely - people orientation, fairness, power sharing, concern for sustainability, ethical guidance, role clarification, and integrity (18) for leaders and their subordinates. The seven dimensions in the ELW was adapted to be applied into the school context for principal and teachers as below:

The first dimension is people orientation which emphasizes the relationship between the principal and teachers through his or her speaking and listening skills; extraordinary care for teachers' welfare and making fair decisions. Second is fairness whereby principals are expected fair-minded and unbiased when handling issues pertaining to teachers work responsibilities, mistakes or problems, misunderstandings and welfare. Third is power sharing which explains ways principals empower teachers to contribute in critical decision-making processes and freely seeks guidance from teachers, delegates challenging tasks equally and provides opportunity for all the teachers to plan their goals. Fourth is concern for sustainability which highlights on principals having concern towards providing a healthy and friendly environment to work. Fifth is ethical guidance which encourages principals to explain work ethics and code of conducts expected at the school. Sixth is role clarification whereby the principal clarifies the roles need to be played and performance expectations of each teacher. The principal also clearly explains each teacher's responsibilities and what is anticipated from working groups. The seventh dimension is integrity which demands principals to hold on to their promises in order to build trust. Principals should be relied upon their actions and words; and trusted to do the things they have said.

\subsection{Trust in Leader}

Trust is viewed in two different perspective - rational and social (19) in a traditional model of trust. Traditionally trust is believed to be developed through social interactions, trustors' character and traits and trustees tendency to be able to develop trustworthiness feelings based on ability, integrity and benevolence (20). Zhu et al., (21) described the concept of trust as - conditional and unconditional trust. Conditional trust is shown when two parties compromise to a deal to be trustworthy to each other. Unconditional trust is built through the shared practice of good values of trustworthiness in a social situation by two parties. A modern model of trust, which integrated several traditional models of trust and presented a set of trustworthy properties - benevolence, competency, integrity, personality characteristics, a history of interactions and openness was developed to cater contemporary organizational changes $(4,22)$. Whitmore (23), conceptualized trust as an attitude (4), perception and belief built by the trustor (teacher) towards the trustee (principal) based on the perceived actions, behaviors, thoughts and values through interpersonal interactions. Leader characteristics thought to influence trust include managerial trustworthy behavior, leader consistency, honesty, integrity, competence, ability, communication, demonstration of concern, benevolence, professional credentials, transactional and transformational leadership style. Many important organizational outcomes are affected by the trust followers have for their leaders, including job performance, support for and commitment to authorities, goal commitment, and follower willingness to behave in ways that benefit the organization, organizational citizenship behavior, and job satisfaction.

The six dimensions of trust discussed widely in this study are benevolence, competency, integrity, personality characteristics, a history of interactions and openness. Bews et al., (4), described these dimensions of trust as "facilitators of trustworthiness" mean- ing traits or character values that contributes to building trust in a leader as stated briefly below:

The first-dimension benevolence identifies principals to be reliable at any faced situation, being easily approached by teachers to solve an issue and is seen as good communicators. Secondly the value of competency - where principals are able to exhibit a group of skills, competencies and characteristics that allows them to have influence in the work place like highly skilful and knowledgeable in the work or a specific dimension, fast thinking and creative, risk takers, proactive, optimistic. Thirdly practicing integrity where the principal demonstrates action that matches what is said or told verbally. Being truthful, following laws and abiding to values preached. Fourthly having personality characteristics like cooperative, diligent, hardworking, emotionally stable, resourceful, concern over work performance. The fifth dimension is having a history of interactions like positive long term interactive two way communicative relationship such as being tight lipped, keeps matters confidential, share good and positive conversation, shows understanding and empathy, aware of what to share. Lastly practicing openness whereby principal is able to communicate necessary information in an open, honest manner and tells teachers the truth about changes in the school.

\subsection{Problem Statement}

The emergence of research on ethical leadership practices was initially focused to the work context of industries, private sectorial task forces, multinational companies, factories and work environment run by managers in the office rather than schools. In the recent times, problems pertaining to school administration and management affecting teacher work place performance is in the rise. Teachers are facing burnout, working meaninglessly, not able to focus and stay enthusiastic while at work. Previous studies on modern leadership styles may have contributed to teacher job satisfaction. Fullan (24), stated the urgency to intervene leadership with moral actions that is possible to transform schools of this generation. According to his work, value based leaders worked passionately and intelligently with people to benefit the most out of them. This study aims at looking into building trust in leader through a value based leadership style - ethical leadership. Hence, assessing the influence of ethical leadership practice in building trust is vital. Research pertaining to ethical leadership and trust is evidently in a slow growing stage in Malaysia. Minimal has been explored in the context of school and educational platforms. In this study, the practice of ethical leadership is emphasized looking at school challenges these days pertaining to human actions and reactions leading towards loss of trust in leaders.

\subsection{Research Objectives}

This case study aims at presenting empirical data based on the objectives below:

1.To identify the level of ethical leadership practiced among secondary school principals and trust in their principal as perceived by teachers.

2.To identify the correlation between ethical leadership practices and trust in leader in the school context.

3.To identify the sub-constructs of ethical leadership practices that significantly contributes to developing trust in leaders.

\section{Review of Literatures}

Previous established researches that underpinned value-based leadership models and human capital theory framed this research study. In recent years, a research by (1) in South Africa, presented a structural modal representing the relationship between ethical leadership, trust and work engagement in the private business context. The research showed positive relationship from the structural equation model used between a) ethical leadership and trust $b$ ) 
trust and work engagement c) ethical leadership and work engagement among managers and employees.

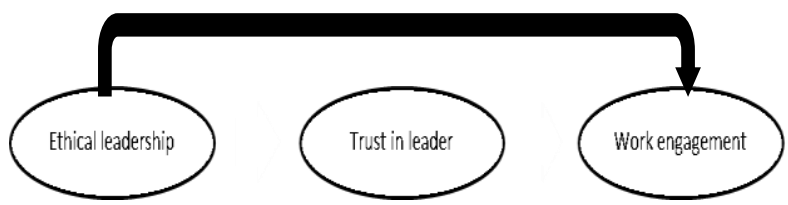

Figure 1: Structural modal: Relationship between Ethical leadership, Trus and Work Engagement.

Source: Engelbrect et al. (1)

Bello (17) shared reviews of various scholars on the concept of ethical leadership and the effect on job performances. Employee performance seem to increase when trust and confidence on leadership traits are built. Unethical decision-making leads to increase of distrust and lack of job commitment. Employees start trusting their leaders and perform better in their assigned task when their leaders constantly demonstrate ethical traits.

Leh et al., (25), conducted a study on the practice of trust towards leaders in the educational organizations. Trust and commitment were discussed for better understanding of ethical leadership and employee job performance. It is the leader's key responsibility to create an environment of mutual trust. This being a challenging duty, takes time but once the culture of trust starts to exist in an organization it is a strong sign of unity and commitment among members. This is consistent with the leader-member exchange theory that emphasizes mutual and two-way relationship that benefits both leader and member in the aim of achieving a common goal. The result suggested the use of a better instrument to measure trust in the educational context or a modification in the in strument making it more comprehensive and relevant. Organisational trust is said to be a panacea to employee's lack of motivation and dedication to work. Non-existence of trust can reduce the enthusiasm and commitment of the teachers and restrict the expansion and development of the school.

Good working relationship and organisational trust was found to create a positive working attitude that brought about the feeling of security, needed by the immediate leader as well as putting greater efforts in work (26). Nevertheless, Sibamba's detailed study on trust and work engagement among banking staffs in South Africa, revealed that trust in the organisation only had significant relationship with physical work engagement and no significant relationships with emotional and cognitive engagement. Previous studies shared communication to be the factor of sustaining trust in organisational challenging situations.

Norman et al., (27), linked trust with leaders' positivity and transparency in challenging organisational situations like company "downsizing". The mixed mode study, showed results of leaders' positivity and transparency as being impactful towards employee's perceived trust in such turmoil.

\section{Methodology}

This study investigates and explores the relationship between teacher perceptions of ethical leadership practices and trust on their leaders in secondary schools. Ethical leadership practices among principals acts as the independent variable and trust in leader acts as the dependent variable. The dimensions of each variable is illustrated in the diagram below (Refer Figure 2).

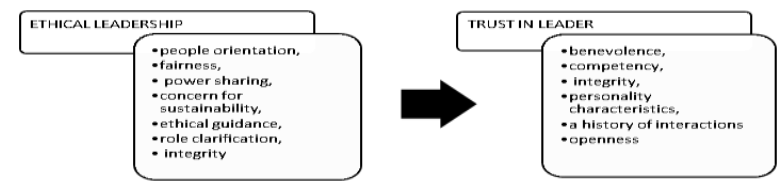

Figure 2: Research Model

\subsection{Research Design}

This cross-sectional survey study took up the design of a case study procedure. It is a pioneer study that will represent a snapshot of a phenomena, to a research that will be proceeded to in the near future. The case involved 31 complete responses and system selected to be analysed to answer the research questions. This research utilized an electronically emailed survey which was shared among educators of the national type secondary schools in order to collect data. Ethical leadership practices is measured with Ethical Leadership at Work (ELW) questionnaire and trust in leader is measured using the Trust in Leader (TL) questionnaire. Both questionnaires were adapted and adopted into this study according to the relevance of the context of the research - schools. Both questionnaires have no past evidence or traces of being used in the local secondary school context to measure similar variables. Questionnaires were validated by four local experts full-filing content and construct validation processes before the questionnaires were distributed.

Descriptive statistics such as mean (M) and standard deviation (SD) will be analysed using the Statistical Package for Social Sciences (SPSS) for Window Version 22.0 in the aim of answering the research questions 1,2 and 3 as stated in Table 1 below. This study interprets the coefficient, $r$ value based on Alias (1997) Refer Table 2 below. The measurement scale used in this particular study is a 5 point Likert scale categorised into three groups:

Table 1: Mean Score Interpretation

\begin{tabular}{|l|l|}
\hline Mean Score & Interpretation \\
\hline 1.00 to 1.99 & Low \\
2.00 to 2.99 & Moderate \\
3.00 and above & High \\
\hline
\end{tabular}

Table 2: Correlation Coefficient Value Interpretation

\begin{tabular}{|c|c|}
\hline $\begin{array}{c}\text { Correlation } \\
\text { Coefficient }(\mathbf{r})\end{array}$ & Interpretation \\
\hline \pm 0.01 to \pm 0.20 & Very weak/Very small \\
\hline \pm 0.21 to \pm 0.40 & Weak/Small \\
\hline \pm 0.41 to \pm 0.60 & Moderate/Medium \\
\hline \pm 0.61 to \pm 0.80 & Strong/Large \\
\hline \pm 0.81 to \pm 0.10 & Very Strong \\
\hline
\end{tabular}

\subsection{Sampling}

This study utilized the random sampling approach. Participation in this pilot study was voluntary. After the validation of the instruments, a few national type secondary schools were contacted via e-mail to voluntarily participate in this study. Schools that responded were given the survey URL to complete the survey. Teachers who were interested to participate completed the questionnaire with the full understanding that they were doing this at their own free will. 41 teachers responded to the survey. 31 survey was considered complete and the data was used to further be analyzed for this pilot study.

\subsection{Instrument}

The instrument chosen was adapted and developed based on Ethical Leadership at Workplace questionnaire (ELW). (6). The ethical leadership behaviour dimensions are categorised in 7 domains fairness, power sharing, role clarification, people orientation, integrity, ethical guidance and concern for sustainability were measured by a total of 38 items. For Trust in Leaders (TL) Questionnaire, the instrument chosen was adapted and adopted from (4). The trust in leader questionnaire has 12 items which originally consists of 47 items. The instruments were validated before the pilot study commenced. The instruments were strongly reliable with Cronbach Alpha values of 0.954 and 0.981 respectively. All title and author details must be in single-column format and must be centred. 


\section{Results and Findings}

\subsection{Level of Ethical Leadership Practiced among Sec- ondary School Principals and Trust in their Principal as Perceived by Teachers.}

Level of ethical leadership practiced among secondary school principals and trust in their principal are both at high level as shown in Table 3.

Table 3: Level of EL and TL

\begin{tabular}{|l|l|c|c|}
\hline & Mean & Std. Deviation & N \\
\hline Ethical Leadership & 3.3964 & .63718 & 31 \\
\hline Trust In Leader & 3.3548 & 1.18458 & 31 \\
\hline
\end{tabular}

\subsection{Correlation between Ethical Leadership Practices and Trust in Leader in the School Context.}

Table 4 shows the correlation between ethical leadership practice and trust in leader was investigated using Pearson productmoment correlation coefficient. There was a very strong positive correlation between ethical leadership and trust in leader ( $\mathrm{r}=0.897$, $\mathrm{n}=31, \mathrm{p}<0.05$ ) among school principals and teachers.

Table 4: Correlation of EL and TL

\begin{tabular}{|l|c|c|c|}
\hline \multicolumn{2}{|l|}{ Trust In Leader } & \\
\hline $\mathbf{N}$ & $\mathbf{r}$ & $\mathbf{P}$ & $\begin{array}{l}\text { Strength of } \\
\text { Relationship }\end{array}$ \\
\hline 31 & $0.897 * *$ & 0.000 & Very Strong \\
\hline
\end{tabular}

There is a statistically significant correlation between respondent's perception on the level of ethical leadership practice in their principals and their level of trust in their leaders (principals) because the Sig. 2- tailed level is .000. Which means, when ethical leadership practices increases, the level of trust also increases. Ethica leadership practices very strongly influences the building of trust.

\subsection{Sub-Constructs of Ethical Leadership Practices that Significantly Contributes to Developing Trust in Lead- ers.}

It is clear that there is a positive correlation $(p<0.001)$ between the development of trust in leader construct and the sub-constructs of ethical leadership practices. Based on importance, the integrity sub-construct had the greatest impact (estimate $=$ 0.924; $p<0.001$ ) and followed by people orientation (estimate $=$ $0.899 ; p<0.001$ ), concern for sustainability (estimate $=0.795 ; p<$ 0.001 ), ethical guidance (estimate $=0.782 ; p<0.001$ ), role clarification (estimate $=0.759 ; p<0.001$ ) and power sharing (estimate $=0.678 ; p<0.001)$. The weakest sub-construct was fairness (estimate $=0.012 ; p<0.001$.

Table 5: Correlation between trust in leader construct and the subconstructs of ethical leadership

\begin{tabular}{|l|c|c|}
\hline Ethical Leadership & $\begin{array}{c}\text { Trust In Leader } \\
\mathbf{r}\end{array}$ & $\begin{array}{c}\text { Strength of } \\
\text { Relationship }\end{array}$ \\
\hline People Orientation & .899 & Very Strong \\
Fairness & .012 & Very Weak \\
Power Sharing & .678 & Strong \\
Concern for & .795 & Strong \\
$\quad$ Sustainability & .782 & Strong \\
Ethical Guidance & .759 & Strong \\
Role Clarification & .924 & Very Strong \\
Integrity & & \\
\hline
\end{tabular}

\subsection{Conclusions}

The current study on the relationship between ethical leadership

and trust in leader effectiveness has implications for both theory

The results demonstrated that the two main practices - integrity, and people orientation (Refer Table 5) were critical measures of building trustworthiness or trust in a leader in the school context.

\section{Discussion}

This case study empirically investigated the impact of ethical leadership practices in developing trust in leaders through the practice of ethical leadership in school administrative, management, instructions and teachers welfare. Drawing in the results of past and present researches, this case study suggests that the practice of ethical leadership style, helps in large to develop trust in tive working climates and behavior especially in schools. The pilot study shares the sub-constructs of ethical leadership practices that precisely would cater to the development of trust among teachers and principals.

In this case study, it was found that there was a statistically significant and positive relationship between ethical leadership and trust in leaders. This is consistent to the findings by (1), who found that ethical leadership practices contributed greatly to the development of trust. Ethical leadership promotes good values that influences the development of trustworthy feelings towards leaders. The demonstrations of honesty, dedication and being open are parallel values in leaders who are trusted by their followers.

Integrity showed as the strongest predictor of developing trust in leaders followed by people orientation, concern for sustainability, ethical guidance, role clarification and power sharing. Integrity demands the leader to be honest and to speak the truth even if the truth was unpleasant. Integrity is also said to be the fundamental of a relationship that makes one become dependable to another (28). A leader with integrity is perceived to be trustworthy and honest at all situations even when they cannot be seen. What they speak is consistent to their actions. What they disclose is in complete and nothing is kept hidden to harm others. In the case of being people orientated, "Trust in the workplace" have shared the importance of placing relationship with people before competency, action and building trust. People oriented leaders make their people feel good about themselves and the work they produce. They put in a lot of effort in creating a professional bond that influences the workers to in return work for the organization and goals.

The weakest predictor was fairness. Being fair did not cater much in building trust among leaders who were practicing ethical leadership. These findings differ from a study conducted by (29) whereby people orientation and role clarification subsequently became the sub-constructs of ethical leadership that had the greatest impact towards organizational commitments.

\subsection{Recommendations}

The data collected from this study is therefore recommended as strong catalyst to further investigate if both variables of this case study will facilitate or mediate other variables in similar contexts. Findings of the study are highly recommended to be shared by training institutions of school leadership and teacher capital or professional development related to participants. Trainers can specifically plan training slots to identify challenges that can be solved via ethical leadership practices. The items in the survey can be used as a checklist or daily audit to practice ethical leadership and developing trust. As leaders become clearer and aware of ethical practices, they can share the benefits or outcomes in small group discussions or effective problem-solving strategy meetings. This study is also strongly recommended to be conducted in a larger scale for wider sample size. leaders which further may cater to the needs of developing posi- 
and practice; and organizational work behavior and work motivation in general. First, the pilot study has confirmed the existence of a relationship between ethical leadership and trust in leaders in Malaysian secondary schools. Second, the study has added valuable findings and knowledge to the field of ethical leadership and building trust in leaders to the education platform. Thirdly, apart from catering teachers with professional development inputs as a way to care for teacher's well-being; building of trust in leaders can be another strong variable to create positive work place behaviors. The findings therefore indicate that school leadership cannot neglect ethical leadership practice of integrity and people orientation as most essential to their success if they must be effective in their leadership and overall school improvement undertakings. Leader integrity as aspired in the National Integrity Plan (NIP) is a catalyst to improve organizational wellbeing and the quality of life in general.

The dimensions of ethical leadership discussed in this study strongly helps in the nurturing of trust in leaders in the school context. School leaders can improve their leadership skills, competency as principals and re-establish better reputation by understanding the nature of ethical leadership and how it can work in building trust in leaders. Trust between leader and member strengthens the organisation and its functions. In this case, the entire school system can be improved in terms of teacher productivity, teacher-administrator relationship, instructional qualities, work satisfaction, student outcomes and positive school working climate. Trust is the fundamental mediator between the leadermember relationship.

\section{Acknowledgement}

Special gratitude to my academic supervisors and partners towards the success of this research, commitment and participation.

\section{References}

[1] Engelbrecht AS, Heine G, Mahembe B. The influence of ethical leadership on trust and work engagement: An exploratory study. SA Journal of Industrial Psychology. 2014 Jan 1;40(1):1-9.

[2] Chughtai A, Byrne M, Flood B. Linking ethical leadership to employee well-being: The role of trust in supervisor. Journal of Business Ethics. 2015 May 1;128(3):653-63.

[3] Bligh MC. Leadership and trust. InLeadership Today 2017 (pp. 21 42). Springer, Cham.

[4] Bews N, Martins N. An evaluation of the facilitators of trustworthiness. SA Journal of Industrial Psychology. 2002 Jan 1;28(4):14-9.

[5] Yozgat U, Meșekıran G. TheImpact of Perceived Ethical Leadership and Trust in Leader on Job Satisfaction.

[6] Den Hartog DN, Belschak FD. Work engagement and Machiavellianism in the ethical leadership process. Journal of Business Ethics 2012 Apr 1;107(1):35-47.

[7] Darcy KT. Ethical leadership: The past, present and future. International Journal of Disclosure and Governance. 2010 Aug 1;7(3):198212.

[8] Frank DG. Meeting the ethical challenges of leadership. Journal of Academic Librarianship, 2002 28(1/2), 81.

[9] Davis CM. Elementary Teachers' Perceptions of Administrators and Job Satisfaction. University of Cincinnati; 2012.

[10] Mihelic KK, Lipicnik B, Tekavcic M. Ethical leadership. International Journal of Management \& Information Systems (Online). 2010 Jan $1 ; 14(5)$.

[11] Starratt, RJ. Ethical leadership (Vol. 8). Jossey-Bass.2004.

[12] Northouse PG. Leadership: Theory and practice. Sage publications; 2013.

[13] Saat MM, Jamal NM, Othman AN. Lecturers' and students' perceptions on ethics in academia and lecturer-student interaction. Research Management Centre, Universiti Teknologi Malaysia. Retrieved from http://eprints. utm. my/2745/1/71989. pdf. 2004

[14] Stob, h. (1978). Ethical reflections: essays on moral themes.

[15] Brown ME, Treviño LK. Ethical leadership: A review and future directions. The leadership quarterly. 2006 Dec 1;17(6):595-616.
[16] Trevino LK, Hartman LP, Brown M. Moral person and moral manager: How executives develop a reputation for ethical leadership. California management review. $2000 \mathrm{Jul} ; 42(4): 128-42$.

[17] Bello SM. Impact of ethical leadership on employee job performance. International Journal of Business and Social Science. 2012 Jun 1;3(11).

[18] Kalshoven K, Den Hartog DN, De Hoogh AH. Ethical leadership at work questionnaire (ELW): Development and validation of a multidimensional measure. The Leadership Quarterly. 2011 Feb 1;22(1):51-69.

[19] Hung YT, Dennis AR, Robert L. Trust in virtual teams: Towards an integrative model of trust formation. In System Sciences, 2004. Proceedings of the 37th Annual Hawaii International Conference on 2004 Jan 5 (pp. 11-pp). IEEE.

[20] Mayer RC, Davis JH, Schoorman FD. An integrative model of organizational trust. Academy of management review. 1995 Jul 1;20(3):709-34.

[21] Zhu W, May DR, Avolio BJ. The impact of ethical leadership behavior on employee outcomes: The roles of psychological empowerment and authenticity. Journal of Leadership \& Organizational Studies. 2004 Aug;11(1):16-26.

[22] Bews, N.F., and Rossouw, G.J. "Contemporary Organisational Change And The Importance Of Trust". SA Journal of Industrial Psychology, 2002, 28 (4), 2-6

[23] Whitmore, CB. (2007). Development of trust in leadership: exploring a cognitive process model (doctoral dissertation, virginia tech).

[24] Fullan M, editor. The moral imperative of school leadership. Corwin press; 2003 Mar 12.

[25] Leh Ly, Abdullah Ag. Practice Of Trust Towards Leaders In The Educational Organizations.

[26] Sibamba VM. The role of trust in job satisfaction and work engagement among bank employees (Doctoral dissertation, NorthWest University (South Africa), Potchefstroom Campus).2017.

[27] Norman SM, Avolio BJ, Luthans F. The impact of positivity and transparency on trust in leaders and their perceived effectiveness. The Leadership Quarterly. 2010 Jun 1;21(3):350-64.

[28] Heathfield SM. What Is Integrity-Really? Honesty and Trust Are Integral to Integrity as These Examples.2018 March 10

[29] Ismail IB, Daud YB. Influence of ethical leadership towards organisational commitment. International Journal of Scientific and Research Publications. 2014;4(9):1-6. 